\title{
U so do dietil-estilbestrol no tratamento do priaspismo em pacientes com doença falciforme - Relato de dois casos e uma a revisão da literatura
}

Rodolfo D. Cançado ${ }^{1}$

Dante M. Langhi Jr.

Carlos S. Chiattone

Sérgio A. B. Brasil ${ }^{1}$

Ana C. Marret ${ }^{1}$

Flávio A. Naoum ${ }^{3}$
Priapismo é a ereção dolorosa e persistente do pênis, associado ou não ao estímulo sexual. A prevalên cia de priapismo em pacientes com doen ça falciforme é de $2 \%$ a $11 \%$, embora estudos retrospectivos ten ham demonstrado que $30 \%$ a $45 \%$ dos pacien tes relatam um ou mais episódios de priapismo.

Priapismo prolongado éuma emergência urológica que requer intervenção urgente a fim de evitar fibrose irreversível do pênis e impotência. Diversos procedimentos terapêuticos, incluindo: hidratação, analgesia, eritrocitaférese, vasodilatadores, hidroxiuréia, hormônios (dietil-estilbestrol), aspiração do corpo cavernoso e administração local de drogas vasoativas, e tratamento cirúrgico (fístula caverno-esponjosa) têm sido propostos no tratamento do priapismo em pacientes com doença falciforme.

O objetivo deste relato é descrever dois casos clínicos de pacientes com doença falciforme e priapismo que não responderam ao tratamento clínico e hemoterápico, mas obtiveram resolução completa dos episódios agudos com o uso do dietil-estilbestrol.

Rev.bras. hematol.hemoter.,2002,24(2):139-143

Palavras-chave: Priapismo, dietil-estilbestrol

\section{Introdução}

Priapismo consiste da ereção involuntária, dolorosa e persistente do pênis, associado ou não ao estímulo sexual (1). A primeira descrição dessa complicação urológica aguda em pacientes com doença falciforme foi publicada em 1934 (2).

Historicamente, a prevalência de priapismo em pacientes com doença falciforme é estimada entre $2 \%$ e $11 \%$, porém estudos mais recentes têm demonstrado que cerca de $30 \%$ a $45 \%$ desses pacientes relatam pelo menos um episódio de priapismo. 0 primeiro episódio pode ocorrer na primeira década de vida, embora seja mais freqüente após os 12 anos de idade (idade mediana aproximada de 20 anos) e dos pacientes que apresentam tal complicação, a grande maioria ( $80 \%$ a $90 \%$ ) é portadora de anemia falciforme $(3,4,5,6,7,8,9)$.

Os episódios de priapismo ocorrem mais freqüentemente no período noturno, apresentam duração bastante variável (de minutos a horas), podendo ocorrer por vários dias, semanas ou meses. 0 ato sexual, a masturbação e a ingestão de bebida alcoólica podem induzir um episódio agudo, porém o fator precipitante mais freqüente é a ereção noturna espontânea $(5,7,8)$.

1 - Professores assistentes da Disciplina de Hematologia e Oncologia da Faculdade de Ciências Médicas da Santa Casa de São Paulo e do Hemocentro da Santa Casa de São Paulo

2 - Chefe da Disciplina de Hematologia e Oncologia da Faculdade de Ciências Médicas da Santa Casa de São Paulo e do Hemocentro da Santa Casa de São Paulo

3 - Médico Residente da Disciplina de Hematologia e Oncologia da Faculdade de Ciências Médicas da Santa Casa de São Paulo

Correspondência para: Rodolfo Delfini Cançado

Hemocentro da Santa Casa de São Paulo

Rua Marquês de Itú, 579 - 20 andar. CEP: 01223-001. São Paulo. SP

E-mail: rdcan@uol.com.br 
Basicamente, são descritos dois padrões distintos de priapismo: agudo recorrente e agudo prolongado. 0 primeiro é o tipo mais freqüente, os episódios são mais rápidos (em geral, duram menos de 3 horas), noturnos, recorrentes, cessam espontaneamente na maioria das vezes. Os sintomas são menos intensos, porém, repetidos episódios, às vezes mais de um episódio por noite, interferem na qualidade de vida do paciente. 0 padrão agudo prolongado é o tipo mais grave, o episódio pode durar mais de 24 horas, acompanhado de dor intensa, disúria, retenção urinária, edema peniano e/ou escrotal. Não costuma ser recorrente e, freqüentemente, provoca impotência sexual $(7,8,9)$.

Estima-se que $10 \%$ a $30 \%$ dos pacientes que apresentam priapismo evoluem com perda parcial ou completa da função sexual, independentemente do tipo de tratamento recebido (9). O fator determinante mais importante para a preservação da função sexual normal é o tempo de duração do priapismo. Quanto maior o tempo de duração, pior a resposta ao tratamento e maior a chance de ocorrência de impotência sexual, principalmente quando os episódios são muito prolongados ( $>24$ horas) e em pacientes com mais de 15 anos $(4,5,7,8,9)$.

0 tratamento inicial consiste de: hidratação oral ou parenteral, analgesia, alcalinização, repouso e esvaziamento freqüente da bexiga. Nos casos persistentes ou recorrentes, recomenda-se internar o paciente para manter hidratação parenteral e analgesia com opiáceos. Q uando não se obtém resposta satisfatória, preconiza-se eritrocitaférese a fim de reduzir a concentração da hemoglobina $S(<50 \%)$ e, nos quadros mais graves, aspiração do corpo cavernoso associado à administração local de drogas alfa-adrenérgicas (como por exemplo, epinefrina). Quando essas medidas não são eficazes, indica-se o tratamento cirúrgico (fístula caverno-esponjosa) (5).

Diante da resposta insatisfatória em grande porcentagem dos procedimentos acima mencionados, vários regimes de tratamento têm sido preconizados como: bloqueadores dos canais de cálcio, vasodilatadores, pentoxifilina, hidroxiuréia, eritrocitaférese e tratamento hormonal com drogas anti-androgênicas como é 0 caso do dietil-estilbestrol $(3,8)$.

\section{D escrição dos Casos}

0 caso 1 tratava-se de paciente branco, 25 anos, com diagnóstico de anemia falciforme que iniciou episódios noturnos de priapismo

Tabela 1. Resultado do hemograma, reticulócitos e eletroforese de hemoglobina

\begin{tabular}{|l|c|c|}
\hline \multirow{2}{*}{ Teste Laboratorial } & \multicolumn{2}{|c|}{ Resultado (*) } \\
\cline { 2 - 3 } & Paciente 1 & Paciente 2 \\
\hline Hemoglobina (g/dl) & 8,5 & 9,0 \\
\hline Hematócrito (\%) & 25 & 28 \\
\hline Volume Corpuscular médio (fl) & 82 & 76 \\
\hline RDW (\%) & 23,6 & 24,5 \\
\hline Leucócitos (x/mm3) & 14.400 & 12.600 \\
\hline Plaquetas (x/mm3) & 323.000 & 332.000 \\
\hline Reticulócitos (\%) & 4,0 & 5,0 \\
\hline Eletroforese de Hemoglobina & 0,0 & 0,0 \\
\hline Hemoglobina A1 (\%) & 3,2 & 4,9 \\
\hline Hemoglobina A2 (\%) & 2,0 & 2,3 \\
\hline Hemoglobina Fetal (\%) & 94,8 \\
\hline Hemoglobina S (\%) & 92,8 \\
\hline (*) Pacientes em condições basais (sem crise aguda e sem tran ffusão de hemácias) \\
\hline
\end{tabular}

Fonte: SAME - Santa Casa de São Paulo 
diariamente, com duração de 1 a 3 horas por mais de 30 dias. Como não apresentou melhora com hidratação e analgesia, foi submetido a várias sessões de eritrocitaférese com o objetivo de manter a concentração de hemoglobina S entre 30 e $50 \%$, porém com melhora parcial da freqüência e da duração das crises.

0 caso 2 tratava-se de paciente branco, 27 anos, com diagnóstico de $\mathrm{S} /$ Beta $^{0}$ Talassemia que começou a apresentar episódios de priapismo cada vez mais freqüentes e duradouros. Também obteve melhora parcial com os procedimentos adotados no caso 1 . Na tabela 1 relacionamos os resultados dos seguintes exames: hemograma, reticulócitos e eletroforese de hemoglobina de ambos os pacientes.

Os dois pacientes foram tratados com dietilestilbestrol por via oral iniciando com $5 \mathrm{mg} / \mathrm{dia}$ por 5 dias seguido de 2,5 mg/dia por mais 7 a 10 dias ou até o desaparecimento das crises. No caso 1, o paciente não apresentou mais episódio de priapismo a partir do 50 dia do medicamento, permanece sem priapismo há cerca de 12 meses e sem medicação. No caso 2, houve diminuição gradativa da duração e da freqüência das crises. Tal paciente não apresentou nenhum outro episódio de priapismo após o 80 dia da medicação. Nesse caso, após cerca de 15 dias do término do tratamento, o paciente voltou a apresentar episódios de priapismo que desapareceram com a manutenção do medicamento na dose de $2,5 \mathrm{mg} /$ dia, três vezes por semana, seguido de $2,5 \mathrm{mg} / \mathrm{dia}$ uma vez por semana, por mais duas semanas.

\section{Comentários}

Priapismo é uma complicação aguda freqüente em pacientes com doença falciforme e a perda parcial ou completa da função sexual acomete 10\% a $30 \%$ dos casos (8). Na maioria das vezes, deve-se à dificuldade de drenagem do sangue intracavernoso sendo classificado como tipo hipoxêmico, de baixo fluxo ou venoso (4).

Embora sua patofisiologia não esteja totalmente elucidada, sabe-se que a desidratação e a hipoventilação resultam em acidose metabólica e diminuição da tensão do oxigênio. Essas alterações, que ocorrem fisiologicamente no período noturno, promovem menor deformabilidade dos eritrócitos e maior risco de falcização das hemácias dificultam a drenagem sangüínea do corpo cavernoso e favorecem o priapismo $(5,8)$.

0 tratamento ideal para esta complicação ainda não está bem estabelecido. As medidas terapêuticas iniciais recomendadas como: hidratação oral ou parenteral, alcalinização para minimizar a acidose, analgesia e repouso, são importantes e podem ser satisfatórias nos casos mais leves de priapismo. Entretanto, pode ser necessário manter o paciente internado por vários dias a fim de garantir 0 tratamento adequado e o sucesso do seu resultado.

A transfusão de hemácias e, particularmente, a eritrocitaférese possibilita diminuir a concentração da hemoglobina S e manter valores da hemoglobina e do hematócrito mais elevados (cerca de $10 \mathrm{~g} / \mathrm{dl}$ e $30 \%$, respectivamente). Esse tipo de tratamento está indicado nos quadros mais graves e prolongados que não obtiveram resposta satisfatória às medidas iniciais. 0 pequeno número de estudos publicados, em geral com poucos pacientes, sugere que, para o tratamento do priapismo, esse procedimento é eficaz em alguns casos (12, 13, 14, 15). Além disso, relatos da ocorrência de complicações neurológicas graves após eritrocitaférese em pacientes com doença falciforme têm limitado o uso deste procedimento (16).

A aspiração do corpo cavernoso, seguida da administração de drogas alfa-adrenérgicas, tem sido proposta como procedimento seguro e bastante efetivo em promover detumescência peniana rápida e prolongada $(17,18,19)$. A eficácia desse procedimento depende da manutenção das medidas terapêuticas iniciais, da duração do episódio agudo e, particularmente, da prontidão e da experiência da equipe médica que presta 0 atendimento ao paciente.

Como a rapidez com que se obtém a detumescência do pênis é importante para evitar a impotência, a aspiração do corpo cavernoso seguida da administração de drogas alfa-adrenérgicas está indicada nos casos de priapismo agudo prolongado (mais que 6 horas de duração). Se não houver detumescência do pênis em algumas horas, está indicada a eritrocitaférese com o objetivo de reduzir a concentração da hemoglobina $\mathrm{S}$.

0 tratamento cirúrgico consiste da realização de comunicação entre o corpo cavernoso e o 
corpo esponjoso ou a veia safena. Trata-se de um procedimento invasivo, com elevadas taxas de falha do tratamento e freqüentes complicações. Portanto, está indicado nos casos mais graves e que não responderam às modalidades terapêuticas mencionadas $(20,21,22,23)$.

Nos últimos anos, têm-se demonstrado que vários agentes quimioterápicos são capazes de aumentar a produção da hemoglobina fetal, através da estimulação da síntese da cadeia gama. 0 uso destas drogas tem se mostrado benéfico em pacientes portadores de hemoglobinopatias, particularmente nas doenças falciformes, uma vez que 0 aumento da hemoglobina fetal tem efeito inibidor sobre a polimerização intracelular determinando diminuição dos fenômenos vasooclusivos e menor grau de hemólise (10).

A hidroxiuréia é o agente quimioterápico mais utilizado nestes pacientes e os melhores resultados terapêuticos com a administração desta droga têm sido observados nos pacientes com crises vasooclusivas graves e na síndrome torácica aguda. Embora os resultados sejam bastante variáveis, este medicamento pode ser utilizado nos pacientes com episódios agudos recorrentes de priapismo $(10,11)$.

O utra opção terapêutica que tem sido preconizada nos pacientes com doença falciforme e episódios de priapismo é o uso de drogas antiandrogênicas como é o caso do dietil-estilbestrol. Trata-se de um estrógeno não-esteroidal de estrutura e potência similares ao estradiol, com a vantagem de apresentar boa absorção gastrointestinal e efeito farmacológico mais prolongado.

Apesar do pequeno número de relatos na literatura, dietil-estilbestrol tem-se mostrado uma droga bastante eficaz no tratamento dos episódios recorrentes e na prevenção de novos episódios de priapismo nos pacientes com doença falciforme. Embora seu mecanismo de ação não seja bem conhecido, parece que essa droga bloqueia a produção de testosterona e, provavelmente, tenha efeito direto sobre a reologia eritrocitária. Descreve-se, como efeitos colaterais, sintomas gastrointestinais leves, ginecomastia, disfunção da ereção em indivíduos normais. Entretanto, esses efeitos são raramente observados quando essa medicação é utilizada em doses baixas e por períodos curtos $(3,5,8,9)$.
O importante, após o uso de uma dose inicial de ataque mais elevada, é determinar qual a dose terapêutica de manutenção ideal capaz de manter normal a função sexual e prevenir novos episódios de priapismo (3).

Recomenda-se dose inicial de ataque mais elevada ( $5 \mathrm{mg} /$ dia) até a completa normalização do quadro seguido de dose terapêutica de manutenção capaz de manter normal a função sexual e prevenir novos episódios de priapismo. Esse objetivo é normalmente obtido com administração de $2,5 \mathrm{mg} / \mathrm{dia}, 3$ vezes por semana, por 2 a 4 semanas.

\section{Conclusão}

Dietil-estilbestrol é uma droga de fácil utilização, de resposta rápida, e com efeitos colaterais seguramente menos importantes que os relacionados às transfusões de sangue e aos procedimentos invasivos. É uma droga que deve ser melhor estudada, mas sem nenhuma dúvida, deve fazer parte do arsenal terapêutico do tratamento do priapismo nos pacientes portadores de doença falciforme.

Theuse of diethylstilboestrol in thetreatment of priapism in sickle cell disease patients T wo case reportsand a review of theliterature Rodolfo D. Cançado, Dante M. Langhi Jr., Carlos S. Chiattone, Sérgio A. B. Brasil, Ana C. Marret, Flávio A. Naoum

\section{Abstract}

Priapism is a painful and persistent erection usually unassociated with sexual stimulation. Theprevalence of priapism in patients with sickle cell disease is $2 \%$ to $11 \%$. Retrospectivestudies indicatethat $30 \%$ to $45 \%$ haveexperienced priapism on oneor moreoccasions. Prolonged priapism isa urologic emergency requiring urgent intervention to avoid irreversiblepenilefibrosis and impotence. Several therapeutic procedures, including hydration, analgesics, erythrocytapheresis, vasodilators, hydroxiurea, hormones (diethylstilboestrol), aspiration of blood from the corpora cavernosa and intrapenile injections of vasoactivedrugsand surgical procedure(cavernosa- 
spongiosum shunt) have been proposed for the treatment of priapism in sickle cell patients.

The aim of this article is to describetwo clinical cases of sickle cell disease patien ts with priapism who did not respond to the clinical and hemotherapeutic treatment but obtained complete resolution of the acute episodes taking diethylstilboestrol.

Rev.bras.hematol.hemoter.,2002,24(2):139-143

Keywords: Priapism, diethylstilboestrol

\section{Referências Bibliográficas}

1. Nelson JH, Winter CC. Priapism: evolution of management in 48 patients in a 22-year series. J. U rol. 1977; 117:455-458.

2. Oberndorf CP. Priapism of psychogen ic origin . Arch. N eurol. Psych. 1934; 31:1292-1296.

3. Serjeant GR, Ceulaer K, Maude GH. Stilboestrol and stuttering priapism in homozygous sickle cell disease. Lancet 1985; 2:1274-1276.

4. Fowler Jr JE, Koshy M, Strub M, Chinn SK. Priapism associated with the sickle cell hemoglobinopathies: prevalence, natural history and sequelae. J. U rol. 1991; 145:65-68.

5. Hakim LS, Hashmat AI, Macchia RJ. Priapism. In: Sickle Cell Disease: Basic Principles and Clinical Practice. Embury, S.H.; Hebbel, R.P.; Mohandas, N.; Steinberg, M.H., Raven Press Ltd, New York, 1994.

6. Chakrabarty A, Upadhyay J, Dhabuwala CB, Sarnaik S, Perlmutter AD, Connor JP. Priapism associated with sickle cell hemoglobinopathy in children: long-term effects on potency. J. U rol. 1995; 155:1419-1423.

7. Mantadakis E, Cavender JD, Rogers ZR, Ewalt DH, Buchanan GR. Prevalence of priapism in boys with sickle cell anemia. J. Pediatr. H ematol. O ncol. 1999; 21:518-522.

8. Bruno D, Wigfal, DR, Zimmerman SA, Rosoff PM, Wiener JS. Genitourinary complications of sickle cell disease. J. U rol. 2001; 166:803-811.

9. Emond AM, Holman R, Hayes RJ, Serjeant GR. Priapism and impotencein homozygoussicklecell disease. Arch. Intern. M ed. 1980; 140:1434-1437.

10. Charache S. Experimental therapy of sickle cell disease. Am. J. Pediatr. H ematol. O ncol. 1994; 16:62-66.
11. Al Jama AH, AI Dabbous IA. Hydroxyurea in the treatment of sicklecell associated priapism. J. U rol. 1998; 159:1642-1643.

12. Seeler RA. Priapism in children with sickle cell anemia: succesfful management with liberal red cell transfusions. Clin. Pediatr. 1971; 10:418-419.

13. Seeler RA. Intensive transfusion therapy in boys with sickle cell anemia. J. U rol. 1973; 110:360-361.

14. Walker Jr EM, Mitchum EN, Rous SN, Glassman AB, Cannon A, Mclnnes BK. Automated erythrocytopheresis for relief of priapism in sickle cell hemoglobin opathies. J. U rol. 1983; 130:912-916.

15. Rifkind S, Waisman J, Thompson R, Goldfinger $D$. RBC exchange pheresisfor priapism in sickle cell disease. JAM A 1979; 242:2317-2318.

16. Rackoff WR, Ohene-Frempong K, Month $S$, Scott JP, Neahring B, Cohen A R. Neurologic events after partial exchange transfusion for priapism in sickle cell disease. J. Pediatr. 1992; 120:882-885.

17. Sayer J, Parsons CL. Successful treatment of priapism with intracorporeal epinephrine. J. U rol. 1988; 140:827.

18. Molina L, Bejany D, Lynne CM, Politano VA. Diluted epin ephrine solution for the treatment of priapism. J. U rol. 1989; 141:1127-1128.

19. Mantadakis E, Ewalt DH, Cavender JD, Rogers ZR, Buchanan JR. Outpatient penile aspiration and epinephrine irrigation for young patients with sickle cell anemia and prolonged priapism. Blood 2000; 95:78-82.

20. Ebbehoj J. A new operation for priapism. Scand. J. Plast. Reconstr. Surg. 1975; 8:241-242.

21. Noe HN, Wilimas J, Jerkins GR. Surgical management of priapism in children with sickle cell anemia. J. U rol. 1981; 126:770-771

22. Winter CC. Cure of idiopathic priapism: new procedure for creating fistula between glans pen is and corpora cavernosa. U rology 1976; 8:389-391.

23. Datta NS. A new technique for creation of a cavernoglandular shunt in the treatment of priapism. J. U rol. 1986; 136:602-603.

Recebido - 18/03/2002

Aceito - 07/06/2002 